\title{
Bioimpedance Evaluation of Body Fat Composition in Congolese HIV-Infected Patients under Antiretroviral Therapy Regimen Non-Containing Protease Inhibitors nor Stavudine
}

Jean-Robert Rissassy Makulo ${ }^{1,2^{*}}$, Djuma Lukonga ${ }^{1}$, Augustin Luzayadio Longo ${ }^{1,2}$, Jean De Dieu Manyebwa ${ }^{1,3}$, Tresor Monsere ${ }^{1,2}$, Ernest Kiswaya Sumaili, ${ }^{1,2}$ Hippolyte Nanituma Situakibanza ${ }^{1,3}$, Jean Bosco Lasi Kasiam ${ }^{1,4}$, Roger Mwimba Mbungu ${ }^{1,5}$, Jean-Marie Ntumba Kayembe ${ }^{1,6}$ and Francois Bompeka Lepira ${ }^{1,2}$

${ }^{1}$ Faculty of Medicine, University of Kinshasa, DR Congo

${ }^{2}$ Nephrology Unit, Department of Internal Medicine, University Clinics of Kinshasa, University of Kinshasa, DR Congo

${ }^{3}$ Infectious Diseases Unit, Department of Internal Medicine, University Clinics of Kinshasa, University of Kinshasa, DR Congo

${ }^{4}$ Endocrinology and Metabolic Diseases Unit, Department of Internal Medicine, University Clinics of Kinshasa, University of Kinshasa, DR Congo

${ }^{5}$ Department of Gynecology and Obstetrics, University Clinics of Kinshasa, University of Kinshasa, DR Congo

${ }^{6}$ Pneumology Unit, Department of Internal Medicine, University Clinics of Kinshasa, University of Kinshasa, DR Congo

*Corresponding author: Jean-Robert Rissassy Makulo, Nephrology Unit, University Clinics of Kinshasa, University of Kinshasa, DR Congo, E-mail: jrmakulo@yahoo.fr Received: October 18, 2014; Accepted: November 4, 2014; Published: November 10, 2014

Copyright: ( 2014 Makulo JR, et al. This is an open-access article distributed under the terms of the Creative Commons Attribution License, which permits unrestricted use, distribution, and reproduction in any medium, provided the original author and source are credited.

\begin{abstract}
Background: Protease inhibitors $(\mathrm{PI})$ and stavudine are frequently associated with abnormalities of the body composition. The present study aimed to evaluate the body fat composition of HIV-infected Congolese patients receiving antiretroviral other than $\mathrm{PI}$ or stavudine.

Patients and Methods: Anthropometric measures and body composition of $125 \mathrm{HIV}$-infected Congolese patients (average age 41 years, $76 \%$ women, $74 \%$ on antiretroviral therapy) attending a primary healthcare center was cross-sectionally evaluated. Patients receiving $\mathrm{PI}$ and/or stavudine were excluded. Subclinical abnormalities of body composition, evaluated by bioimpedance (BIA), were defined as elevated percentage of fat mass (FM) and perivisceral fat mass (PVF) and low percentage of total FM.
\end{abstract}

Results: Clinically evaluated abnormalities of fat distribution were rarely seen, with any case of obesity or lipodystrophy. Overweight (16\%) and central obesity $(6.3 \%)$ were present only in a few women. BIA parameters of body fat composition were similar among antiretroviral naive and treated patients. An average higher percentage of FM $(28 \%$ vs. $12.1 \%$; $p<0.001)$ and PVF $(4.0 \%$ vs. $2.3 \%$; $p=0.002)$ were observed in women, with as well as a higher proportion of subjects with high levels of FM $(12.6 \%)$ and PVF $(2.2 \%)$ in the same group. Thinness was observed only in $6 \%$ of patients of whom $83.3 \%$ of men and $68.4 \%$ of women $(p=0.059)$ had low levels of FM.

Conclusion: Subclinical abnormalities of FM were present in these case series without clinically overt fat distribution abnormalities, highlighting the need for early detection of these FM abnormalities.

Keywords: Body composition; Bio-electric impedance; Antiretroviral therapy; HIV black patients

\section{Introduction}

HIV infection is a major public health problem worldwide, especially in sub-Saharan Africa (SSA) [1]. At the beginning of the pandemic, it was observed in approximately $60-90 \%$ of infected patients, severe malnutrition characterized by a significant unwanted excess weight loss of more than $10 \%$ of body weight [2]. The development of highly active antiretroviral therapy (HAART) has certainly improved the survival and quality of life of patients, but it exposed them to multiple metabolic disorders including lipid profile disorders and abnormalities of the body composition [3-5].

Protease inhibitors (PI) and nucleoside reverse transcriptase inhibitors (NRTI), specially the stavudine, are drugs that have been implicated $[3,4]$. PI are associated with alteration of the adipocyte differentiation as well as insulin resistance. In vitro, they also stimulate apoptosis in differentiated adipocytes.

The NRTI do not affect the process of adipocyte differentiation in vitro. However, there is some evidence for the hypothesis of mitochondrial toxicity as responsible for lipoatrophy induced by these drugs; this would also explain hyperlactatemia, fatty liver with hypertriglyceridemia, polyneuropathy or pancreatic damage sometimes associated with lipodystrophy.

Among the instrumental methods to assess the body composition, the bio-electrical impedance (BIA) is one of the simplest, fastest, more accessible thanks to its low cost and very easy to handle especially in the medical office [6]. Otherwise, a recent study showed that the results of the body composition assessed by the BIA in HIV infected patients had good sensitivity and good specificity compared to the method of dual-energy X-rays absorptiometry (DEXA), which is the gold standard [7]. 
Citation: Makulo JR, Lukonga D, Longo AL, Manyebwa JD, Monsere T, et al. (2014) Bioimpedance Evaluation of Body Fat Composition in Congolese HIV-Infected Patients under Antiretroviral Therapy Regimen Non-Containing Protease Inhibitors nor Stavudine. J Metabolic Synd 3: 168. doi:10.4172/2167-0943.1000168

Page 2 of 4

In the Democratic Republic of the Congo (DRC), generic ARV program has been launched since 2002 using a first line regimen based on a combination of 2 NRTI (AZT, 3TC) and Nevirapine. Since 2006, a second line regimen containing PI has been introduced. Although body composition using BIA has been evaluated in non HIV-infected women [8], no study has yet evaluated the body composition of naive or antiretroviral treated HIV-infected patients. Thus, the aim of the present study was to evaluate the body composition of naive and antiretroviral treated HIV-infected patients seen at a primary healthcare centre of the outskirts of Kinshasa, the capital City and to identify the anthropometric parameter best correlated to perivisceral fat mass (PVF).

\section{Methods}

The present cross-sectional study included all consecutive HIVinfected patients aged $\geq 18$ years who attended from September, 17 to November 6, 2013 the HIV-Outpatient Clinic of Kimbondo Hospital located at the outskirts of Kinshasa, the capital City. The parameters of interest included age, gender, marital status, duration of HIV infection, WHO clinical stage, opportunistic infections and comorbidities, type and duration of HAART, lifestyle habits, personal and family of obesity, height, weight, body mass (BMI), waist circumference (WC), blood pressure (BP), capillary blood glucose, $\mathrm{CD} 4$ cell count and body composition.

Weight was measured using the OMRON BF511 device [9]; with subject without shoes and heavy garments. WC was determined using a tape measure. Seated BP was measured on the left arm after 5 minutes of relaxation using an electronic OMRON M2 basic apparatus; the average of 3 measurements was used for statistical analyses.

Capillary blood glucose was measured by enzymatic method using a Brand One Touch Ultra Glucometer. The body composition was determined by the BIA using a body composition monitor OMRON BF511 [9]. This device determines the percentage of total fat mass (FM) and PVF. Patients on HAART were defined as those who are receiving at least 3 antiretroviral drugs for at least 3 months.

Thinness, normal weight, overweight and obesity were defined as $\mathrm{BMI}<18.5 \mathrm{Kg} / \mathrm{m}^{2}, 18.5-24.9 \mathrm{Kg} / \mathrm{m}^{2}, 25-29.9 \mathrm{Kg} / \mathrm{m}^{2}$ and $\geq 30 \mathrm{Kg} / \mathrm{m}^{2}$. Abdominal obesity was defined as WC $>102 \mathrm{~cm}$ for men and $>88 \mathrm{~cm}$ for women [10]. Lipodystrophy included lipoatrophy and lipohypertrophy defined on the basis of morphological criteria [11].

Percentage of FM and PVF was classified as low, normal, high or very high according to the classification of Gallagher et al. with reference to gender and age [12]. The study received the clearance of the institutional review board and was conducted in respect of Helsinki Declaration with reference to confidentiality and informed consent.

\section{Statistical Analysis}

Whereas the prevalence of lipodystrophy varies between 5 and $8 \%$ in HIV infected-patients not receiving protease inhibitors and stavudine [13], the minimum sample size was calculated at 113 $(\mathrm{p}=1.96 \mathrm{x} 1.96 \times 0.08 \times 0.92 / 0.05 \times 0.05)$. We used SPSS version 20 software for statistical analysis. The Student test and the U Mann-Whitney test were used to compare groups of patients according to the distribution of their variables or not followed the curve of Gauss.
The chi-square test of Pearson was used to compare the degree of association between categorical variables. The correlation between PVF (in \%) and anthropometric parameters was studied using the Pearson correlation test. $\mathrm{P}<0.05$ defined the level of statistical significance.

\section{Results}

A total of 125 patients (76\% women) with a mean age of $41 \pm 10$ years were included in the present cross-sectional study; 92 of them (73.6\%) were receiving a combination in one pill of zidovudine, lamivudine and nevirapine.

\begin{tabular}{|l|l|l|l|l|}
\hline $\begin{array}{l}\text { Variables of } \\
\text { interest }\end{array}$ & $\begin{array}{l}\text { Whole group } \\
\text { (n 125) }\end{array}$ & $\begin{array}{l}\text { on HAART } \\
\text { (n 92) }\end{array}$ & $\begin{array}{l}\text { Naive } \\
\text { (n 33) }\end{array}$ & p \\
\hline Female, \% & 76.0 & 79.4 & 66.6 & 0.112 \\
\hline Age (years) & $41.3 \pm 10.0$ & $39.9 \pm 12.4$ & $47.1 \pm 13.4$ & 0.001 \\
\hline $\begin{array}{l}\text { Family history of } \\
\text { obesity, \% }\end{array}$ & 25.6 & 34.7 & 0 & $<0.001$ \\
\hline Alcohol, \% & 8.0 & 5.4 & 15.2 & 0.087 \\
\hline $\begin{array}{l}\text { Tobacco, \% } \\
\text { Major Ois in the } \\
\text { past, \% }\end{array}$ & 47.2 & 1.1 & 9.1 & 0.056 \\
\hline $\begin{array}{l}\text { Disease duration } \\
\text { (months) }\end{array}$ & $(0-216)^{*}$ & 14.5 & 12.1 & $<0.001$ \\
\hline $\begin{array}{l}\text { Duration } \\
\text { HAART (months) }\end{array}$ & - & 59.8 & $1(0-120)^{*}$ & $<0.001$ \\
\hline HTA,\% & 37.6 & $8(3-216)^{*}$ & - & 0.143 \\
\hline Weight (kg) & $57 \pm 10$ & $57 \pm 9$ & $53 \pm 7$ & 0.010 \\
\hline Size (cm) & $162 \pm 8$ & $162 \pm 7$ & $162 \pm 7$ & 0.740 \\
\hline WC (cm) & $76 \pm 7$ & $21 \pm 3 \pm 7$ & $74 \pm 8$ & - \\
\hline BMI (kg/m ${ }^{*}$ ) & 36.9 & $20 \pm 2$ & 0.44 \\
\hline
\end{tabular}

Table 1: Clinical characteristics of patients. Data expressed as a percentage (\%) or mean \pm standard deviations (SD). ${ }^{*}$ Data expressed as median (minimum and maximum). OIs = opportunistic infections, HAART = highly active antiretroviral therapy, $\mathrm{WC}=$ waist circumference, $\mathrm{BMI}=$ body mass index.

With reference to anthropometric measures, overweight (16\%) and central obesity $(6.3 \%)$ were observed only in women; thinness was present in $13 \%$ of patients without significant gender's differences. Clinical signs suggestive of lipodystrophy were not observed in the present case series.

Tables 1 and 2 summarize general characteristics, anthropometric and body composition parameters of the study population according to treatment status. Compared to naive patients (Table 1), those under ARV therapy were younger $(39.9 \pm 12.4$ vs. $47.1 \pm 13.4$ years; $p=0.001)$ and had in average significantly higher BMI levels ( $22 \pm 3$ vs. $20 \pm 2$ $\left.\mathrm{Kg} / \mathrm{m}^{2} ; \mathrm{p}=0.014\right)$ and proportion of subjects with family history of obesity (34.7 vs. $0 \%$; $\mathrm{p}<0.001)$ and opportunistic infections (59.8 vs. $12.1 \% ; \mathrm{p}<0.001)$. With reference to measures of body composition (Table 2), ARV treated patients tended to have in average a higher 
Citation: Makulo JR, Lukonga D, Longo AL, Manyebwa JD, Monsere T, et al. (2014) Bioimpedance Evaluation of Body Fat Composition in Congolese HIV-Infected Patients under Antiretroviral Therapy Regimen Non-Containing Protease Inhibitors nor Stavudine. J Metabolic Synd 3: 168. doi:10.4172/2167-0943.1000168

Page 3 of 4

percentage of total fat mass; however, the observed difference did not reach the level of statistical significance.

Compared to men, women had in average a significantly higher percentage of total FM $(28 \pm 8.1$ vs. $12.1 \pm 5 \%$; $\mathrm{p}<0.001)$ and PVF $(4 \pm$
2.3 vs. $3 \pm 1.8 \%$; $\mathrm{p}=0.002$ ); they have, however, a significantly lower percentage of muscle mass $(29.1 \pm 3.1$ vs. $41.1 \pm 6.0 \%$; $p<0.001)$.

\begin{tabular}{|l|l|l|l|l|}
\hline Variables of interest & $\begin{array}{l}\text { Whole group } \\
(\mathbf{n} \text { 125) }\end{array}$ & $\begin{array}{l}\text { on HAART } \\
(\mathbf{n} \text { 92) }\end{array}$ & $\begin{array}{l}\text { Naive } \\
\text { (n33) }\end{array}$ & $\mathbf{p}$ \\
\hline CD4 (cells/mm ${ }^{3}$ ) & $303 \pm 184$ & $263 \pm 166$ & $414 \pm 188$ & $<0.001$ \\
\hline Glycemia $(\mathbf{m g} / \mathbf{d l})$ & $107 \pm 23$ & $105 \pm 21$ & $113 \pm 24$ & 0.108 \\
\hline$\%$ of muscle mass & $32 \pm 6$ & $31 \pm 6$ & $33 \pm 6$ & 0.192 \\
\hline$\%$ of total FM & $25 \pm 10$ & $25 \pm 10$ & $22 \pm 8$ & 0.066 \\
\hline$\%$ of PVF & $4 \pm 2$ & $4 \pm 1$ & $4 \pm 2$ & 0.530 \\
\hline
\end{tabular}

Table 2: Biological Characteristics of patients. Data are expressed as mean \pm standard deviations (SD). CD4=Cluster Differentiation; FM=Fat Mass.

Anthropometric correlates of total FM and PVF of the study population are given in Table 3. BMI emerged as the anthropometric parameter best correlated with PVF $(\mathrm{r}=0.56 ; \mathrm{p}<0.001)$ and total FM $(\mathrm{r}=0.56 ; \mathrm{p}<0.001)$.

\begin{tabular}{|l|l|l|l|l|}
\hline \multirow{2}{*}{ Anthropometric parameters } & \multicolumn{2}{|l|}{ Total fat mass } & \multicolumn{2}{l|}{ Perivisceral fat mass } \\
\cline { 2 - 5 } & $\mathrm{r}$ & $\mathrm{p}$ & $\mathrm{r}$ & $\mathrm{p}$ \\
\hline Weight & 0.420 & $<0.001$ & 0.588 & $<0.001$ \\
\hline Size & 0.291 & 0.001 & 0.262 & 0.003 \\
\hline Waist & 0.402 & $<0.001$ & 0.527 & $<0.001$ \\
\hline BMI & 0.568 & $<0.001$ & 0.731 & $<0.001$ \\
\hline
\end{tabular}

Table 3: Correlation between anthropometric parameters and fat mass

\section{Discussion}

The main findings of the present cross-sectional study are as follows: first, the absence of clinical signs of lipodystrophy and the presence of concomitant subclinical body composition abnormalities. Second, ARV treated patients were comparable to naive ones with reference to body composition parameters and proportion of subjects with subclinical body composition abnormalities. Third, BMI emerged as the anthropometric characteristic best correlated to perivisceral fat mass.

Although clinical signs of lipodystrophy were absent, subclinical abnormalities were present in the present case series. It has been reported that although $\mathrm{HIV}$-infected patients with subclinical abnormalities of body fat distribution generally maintain a body mass index in normal or overweight range, they often experience cardio metabolic complications such as dyslipidemia and impaired glucose tolerance similar to those seen in frank obesity [14]. Another large cross-sectional study found more visceral adipose tissue among HIVinfected versus uninfected women, despite similar average BMI in both groups [15]. Previous studies also found that more than half of HIV-infected patients present with abnormal fat accumulation $[14,16]$.

Subclinical body fat composition was similar between ARV-treated and naive patients. This finding in the present case series could have several potential explanations. First, 12 months have been reported to be the average time period necessarily to the development and progression of body fat composition abnormalities in ART-treated HIV [17,18]; the average ART duration in the present case series was 8 months. Second, untreated HIV infection eventually results in wasting, including loss of adipose tissue. Fat gain, which is widely prevalent in the general population and increases with age, may in part be the result of effective ART reversing fat loss due to HIV infection [13]. Third, it has been reported that visceral fat is less influenced by ART than subcutaneous fat, relatively resistant to change in HIV-infected population and influenced by factors others than ART [16].

BMI was best correlated with perivisceral fat mass. This finding agrees with the report by Joy et al. [19]. These authors found that visceral adipose tissue was increased among HIV-infected men and women in the normal ( 18.5 to $24.9 \mathrm{Kg} / \mathrm{m}^{2}$ ) and overweight (25 to 29.9 $\mathrm{Kg} / \mathrm{m}^{2}$ ) categories relative to controls but not among those in the obese category $\left(\geq 30 \mathrm{Kg} / \mathrm{m}^{2}\right)$. In the present post-hoc analysis, the majority of patients were in the normal weight category and obesity was not found.

Difference observed between men and women can be explained by their hormonal profile. Woman undergoes during his sexual life, the influence of hormones to various effects that modulate its weight, either naturally (puberty, cycles, pregnancy, menopause) or due to their therapeutic use (contraception, hormone replacement therapy) [20]. The subclinical abnormalities of body composition associated 
Citation: Makulo JR, Lukonga D, Longo AL, Manyebwa JD, Monsere T, et al. (2014) Bioimpedance Evaluation of Body Fat Composition in Congolese HIV-Infected Patients under Antiretroviral Therapy Regimen Non-Containing Protease Inhibitors nor Stavudine. J Metabolic Synd 3: 168. doi:10.4172/2167-0943.1000168

Page 4 of 4

with other antiretroviral therapy than PI and Stavudine corroborate some recent literature data. Is the case of Van Vonderen et al. who showed that Zidovudine/lamivudine + lopinavir/ritonavir, but not nevirapine + lopinavir/ ritonavir in antiretroviral therapy naive patients, is associated with lipoatrophy and greater relative intraabdominal lipohypertrophy, suggesting other nucleoside inhibitors contributes to lipodystrophy [21].

The interpretation of the results of the present analysis should take into account some limitations. The major limitation of the present analysis is its cross-sectional design precluding temporal and causal relationship of abnormalities of body fact composition with ART and HIV-infection. The use of BIA that is less sensitive than dual Y ray absorptiometry and computerized tomography in assessing body composition [22]. Additional limitations are the small sample size and the lack of repeat measurements of body fat composition which are recommended to increase specificity.

\section{Conclusion}

Subclinical abnormalities of body composition were common finding in the present case series without clinical signs of lipodystrophy. Body composition parameters were similar among ART-treated and naive patients. BMI emerged as the anthropometric parameter best correlated with perivisceral fat mass.

\section{Acknowledgement}

The authors thank the officials and both medical and paramedical staff of the hospital Kimbondo for all facilities granted.

\section{References}

1. Beyrer C, Abdool Karim Q (2013) The changing epidemiology of HIV in 2013. Curr Opin HIV AIDS 8: 306-310.

2. Mocroft A, Brettle R, Kirk O, Blaxhult A, Parkin JM, et al. (2002) Changes in the cause of death among HIV positive subjects across Europe: results from the Euro SIDA study. AIDS 16: 1663-1671.

3. Bedimo RJ (2008) Body-fat abnormalities in patients with HIV: progress and challenges. J Int Assoc Physicians AIDS Care 7: 292-305.

4. Calza L, Manfredi R, Chiodo F (2004) Dyslipidaemia associated with antiretroviral therapy in HIV-infected patients. J Antimicrob Chemother 53: 10-14.

5. Aghdassi E, Arendt B, Salit IE, Allard JP (2007) Estimation of body fat mass using dual-energy X-ray absorptiometry, bioelectric impedance analysis, and anthropometry in HIV-positive male subjects receiving highly active antiretroviral therapy. J Parenter Enteral Nutr 31: 135-141.

6. Baumgartner RN, Chumlea WC, Roche AF (1988) Bioelectric impedance phase angle and body composition. Am J Clin Nutr 48: 16-23.

7. Siqueira Vassimon H, Jordao AA, Albuquerque de Paula FJ, Artioli Machado A, Pontes Monteiro J (2011) Comparison of bioelectrical impedance with skinfold thickness and $\mathrm{x}$-rayabsorptiometry to measure body composition in HIV-infected with lipodistrophy. Nutr Hosp 26:458-464.

8. Mbungu MR, Tandu-Umba NFB, Muls E (2005) Etude de la composition corporelle de la femme noire Congolaise par l'impedance bio-electrique. Congo Medical 4: 25-31.

9. Omron Health Care. Omron BF 511: Body composition monitor, Manual instruction. www.omron-healthcare.com.

10. WHO (2000) The problem of overweight and obesity. Obesity: preventing and managing the global epidemic. Report of a WHO Technical Report Series 894. Geneva: WHO, 537.

11. Mallon PWG (2007) Pathogenesis of lipodystrophy and lipid abnormalities in patients taking antiretroviral therapy. AIDS Rev 9: 3-15.

12. Gallagher D, Heymsfield SB, Heo M, Jebb SA, Murgatroyd PR, et al. (2000) Healthy percentage body fat ranges: an approach for developing guidelines based on body mass index. Am J Clin Nutr 72: 694-701.

13. De Waal R, Cohen K, Maartens G (2013) Systematic Review of Antiretroviral-Associated Lipodystrophy: Lipoatrophy, but Not Central Fat Gain, Is an Antiretroviral Adverse Drug Reaction. Plos One 8: e 63623.

14. Stanley TL, Grinspoon SK (2012) Body composition and metabolic changes in HIV-infected patients. JID 205 (Suppl 3): S383.

15. Brown TT, Xu X, John M, Singh J, Kingsley LA, et al. (2009) Fat distribution and longitudinal anthropometric changes in HIV-infected men with and without clinical evidence of lipodystrophy and HIVuninfected controsl: a substudy of the multicenter AIDS control study. AIDS Research and Therapy 6: 8 .

16. Martinez E, Visnegarwala F, Grund B, Thomas A, Gibert C, et al. (2010) The effects of intermittent, CD4-guided antiretroviral therapy on body composition and metabolic parameters. AIDS 24: 353-363.

17. Feleke Y, Felade D, Mezegebu Y (2012) Prevalence of highly active antiretroviral therapy associated metabolic abnormalities and lipodystrophy in HIV-infected patients. Ethiop Med J 50: 221-30.

18. Monnerat BZ, Cerutti Jr C, Canicali S, Motta RT (2008) Clinical and biochemical evaluation of HIV-related lipodystrophy in an ambulatory population from the Hospital Universitario Antonio de Morais, Vitoria, ES, Brazil. Br J infect Dis 12: 264-68.

19. Joy T, Keogh HM, Hadigan C, Dolan SE, Fitch K, et al. (2008) Relation of body mass index in HIV-infected patients with metabolic abnormalities. J Acquir Immune Defic Syndrome 47: 174-184.

20. Astrup A, Buemann B, Christensen NJ, Madsen J, Gluud C, et al. (1992) The contribution of body composition, substrates, and hormones to the variability in energy expenditure and substrate utilization in premenopausal women. J Clin Endocrinol Metab 74: 279-286.

21. Van Vonderen MG, Van Agtmael MA, Hassink EA, Milinkovic A Brinkman K, et al. (2009) Zidovudine/lamivudine for HIV-1 infection contributes to limb fat loss. PLoS One 21; 4:5647.

22. Browning LM, Mugridge O, Chatfield M, Dixon A (2010) Validity of a new abdominal bioelectrical impedance device to measure abdominal and visceral fat: comparison with MRI. Obesity 18: 2385-2391. 